\title{
STUDY OF SOME RISK FACTORS SUCH AS THE CAUSE OF MUSCLE IMBALANCE AND LUMBAR PAIN
}

\author{
P. Angelova* \\ Medical College, Trakia University, Stara Zagora Bulgaria
}

\begin{abstract}
Back pain is a significant public health problem $-11-12 \%$ of the population suffers from back pain. The aim of the study is to establish the etiology of lumbar pain, the presence of muscle imbalance and a feeling of pain. Materials and methods: the research is conducted of 2018/2019 at the rehabilitation center Kinezi, Stara Zagora, Bulgaria; health outcome data were collected by Test for muscle stiffness, VAS and Roland-Morris Questionnaire. The mean age of all participants $(n=37)$ is $44.3 \pm 15.3(17-70)$ years. Results: the mean $( \pm \mathrm{SD})$ score of VAS of all studied patients at baseline was $5.78 \pm 2.23$; the mean $( \pm \mathrm{SD}) \mathrm{RMQ}$ score at baseline was $6.95 \pm 4.57$. The percentage of those who are never and currently not practicing sport is predominant, and the athletes are just under $1 / 4$. The studied as a risk factor causes of muscle imbalance are divided into 4 groups: trauma; physical exertion; static load-sitting or standing for a longer time or as a working posture; spinal deformities. Conclusion: no statistical significance is observed between the cause and the hypertonus of the examined muscles. In women, it is the most pronounced cause of muscle imbalance there at static load (61.9\%), and for men at physical exertion $(42.8 \%)$.
\end{abstract}

Key words: pain management, measuring the functional status.

\section{INTRODUCTION}

Nonspecific back pain is a significant public health problem globally $-11-12 \%$ of the population suffers from back pain. According to Balagué, Mannion, Pellisé, Cedraschi (1), Radeva et al. (2), Blair (3), Nachemson (4) the spread of pain in the lower back reaches significant over $80 \%$, and the prevalence of chronic pain in the lower back affects around $23 \%$ of the global population. Proper diagnostics include anamnesis and clinical examination, but the use of diagnostic imaging should be limited.

The aim of the study is to establish the presence and degree of muscle imbalance, pain sensation and etiology of lumbar pain.

In pursuance of this objective we have set the following tasks:

\footnotetext{
*Correspondence to: Petya Angelova, Trakia University Medical College, Bulgaria, Stara Zagora 6003, Georgi Apostolov str. 14, E_mail: pe_angelova@abv.bg phone number: $+359886441285$
}

To investigate: demographic indicators, causes of pain, muscle imbalance and altered daily functional activity;

Carry out an analysis of the results and draw conclusions

\section{MATERIALS AND METHODS}

A study of medical documents, history patient data: limitation of complaints, risk factors, occupation, past trauma, accompanying diseases and previous treatment was done. Patients enrolled in the present study are directed for therapy by a general practitioner, a specialist in neurology and orthopedics and traumatology. The leading cause of the search for specialized help is pain, and in others there is a feeling of stiffness in the back, limited daily activity.

Test for muscle stiffness. Static muscles are assessed by the following scale: 0 -absence of shortening, 1- slightly increased tone, 2moderate shortening (50\%), 3-strong shortening. Test administered by a physiotherapist specialist. 
Pain Rating by Visual-Analogue Pain Scale (VAS). The Visual-Analog Pain Scale is used to measure the intensity of the pain. It represents a one-dimensional scale in the form of a straight line of 0 to $10 \mathrm{~cm}(0 \mathrm{~mm}$ to 100 $\mathrm{mm})$ at the beginning and end of which has two descriptors representing extreme pain intensity (0- without pain and 10 extremely severe pain) of each end. Individuals surveyed determine the individual intensity of pain themselves by marking a line on the line that represents their intensity of pain.

\begin{abstract}
Roland-Morris Low Back Pain and Disability Questionnaire (RMQ) for the pain in the lumbar region and the difficulties caused by it. The RMQ has 24 statements describing possible activity restrictions. The scores range from zero (indicating no disability) to 24 (indicating severe disability). The patient is instructed to check each statement that describes a current activity restriction. The RMQ can be used on any routine low back patient, as an outcome measure for monitoring the effect of low back pain on patients' activities, before and during treatment.
\end{abstract}

\section{Statistical methods}

ANGELOVA P.

Numerical variables were presented as mean \pm standard deviation (SD). The Student's test was used compare age and duration of pain between men and women. All statistical analyses were performed using IBM SPSS Statistics for Windows, Version 25.0(Armonk, NY, IBM Corp.). Statistical significant was accepted at $\mathrm{p}<0.05$.

\section{RESULTS}

The mean age of all participants was $44.3 \pm$ 15.3 (17-70) years. The women were 22 (59.5) and men - 15 (40.5). The mean age of the women was $47.8 \pm 14.5(24-70)$ years and for men $39.1 \pm 15.4$ (17-65) years. The mean duration of pain in patients was $4.8 \pm 3.7(0.4$ $17.0)$ years. In women, it was $5.0 \pm 4.5(0.4+$ $17.0)$ and in males $4.4 \pm 2.4(0.6-10.0)$ years. There was no significant difference in age $(\mathrm{p}=0.091)$ and in duration of pain $(\mathrm{p}=0.659)$ for males and females.

There is no statistically difference of mean duration of pain between women and men $-\mathrm{Z}=$ $0.218 ; p=0.827$. There is a positive correlation between age and prescription, i.e. with increasing age increases the duration of pain.

Table 1. Distribution by sports activity

\begin{tabular}{|l|l|l|}
\hline Practicing sport & Number & Percentage \\
\hline No & 28 & 75,7 \\
\hline Yes & 9 & 24,3 \\
\hline Total & 37 & 100,0 \\
\hline
\end{tabular}

By history data (Table 1) in the studied group of 37 people, the percentage of those who are never and not currently practicing sport is predominant, while the athletes are just under $1 / 4$.

\section{Analysis of pain values through VAS-Pain \\ The pain measured by VAS and calculated as an average (mean $\pm \mathrm{SD}$ (Me (range)) is $5.8 \pm$ $2.2(2-10)$. In women, it is $5.9 \pm 2.3(2-10)$ and in males it is $5.7 \pm 2.2(3-9)$. No statistical difference of pain is observed in women and men $-\mathrm{Z}=0.235 ; \mathrm{p}=0.815$. The largest number, to the persons who assess a pain with 4 and 6-7 people, which is an indicator of the average to a high sensation of soreness. Accordingly, the percentage of individuals giving an estimate of 4 and 6 is (18.9). \\ Analysis of the values of the ROLAND MORIS test}

The mean value (Me (range)) is $6.95 \pm 4.57$ (2$22)$. In women is $6.86 \pm 3.82(2-14)$ and males is $7.07 \pm 5.64(2-22)$. No statistical difference is observed in women and men $-\mathrm{Z}=0.318$; $\mathrm{p}$ $=0.795$. In 5 people in the study group, the amount of difficulties due to pain in the lumbar region was 12 out of 24 item, i.e. their percentage was 13.5 . Only 1 person has a total amount of 22.

\section{Analysis of the causes of pain and hypertonus}

The factors studied as a risk factor for muscle imbalance are divided into 4 groups (Table 2): Trauma-falls, surgery, condition after pregnancy and childbirth.

Physical exercise.

Static load-sitting or standing for a longer time or as a working posture.

Spinal deformities (scoliosis). 
Table 2. Distribution by reason

\begin{tabular}{|l|l|l|}
\hline Reason & Number & Percentage \\
\hline Trauma & $\mathbf{6}$ & $\mathbf{1 6 , 3}$ \\
\hline Disc hernia & $\mathbf{5}$ & $\mathbf{1 3 , 5}$ \\
\hline Physical exertion & 7 & $\mathbf{1 8 , 9}$ \\
\hline Static load & $\mathbf{1 7}$ & $\mathbf{4 5 , 9}$ \\
\hline Scoliosis & $\mathbf{2}$ & $\mathbf{5 , 4}$ \\
\hline Total & $\mathbf{3 7}$ & $\mathbf{1 0 0 , 0}$ \\
\hline
\end{tabular}

A moderate statistical significance was detected between the gender and the cause$\chi^{2}=8.128 ; p=0.037 ;$ Cramer's $V=0.482$. In women, it is clearly expressed in a static load $(61.9 \%)$, and in men at physical exertion $(42.8 \%)$ (Table 3).

Table 3. Distribution of Causes in Men and Women

\begin{tabular}{|l|l|l|}
\hline \multirow{2}{*}{ Reason } & \multicolumn{2}{|l|}{ Gender } \\
\cline { 2 - 3 } & women & men \\
\hline Trauma & $4(19.0)$ & $2(14.3)$ \\
\hline Disc hernia & $3(14.3)$ & $2(14.3)$ \\
\hline Physical exertion & $1(4.8)$ & $6(42.8)$ \\
\hline Static load & $13(61.9)$ & $4(28.6)$ \\
\hline
\end{tabular}

After ANOVA application, an effect of age on the type of cause was studied. There is a statistical difference for the four reasons - $\mathrm{F}$ $(31)=6.799 ; \mathrm{p}=0.001$. Post-hoc comparisions show that the mean result for patients with trauma $(\mathrm{M}=36.5 ; \mathrm{SD}=6.5)$ is statistically different from static load $(\mathrm{M}=52.6 ; \mathrm{SD}=$ 13.9) $\mathrm{M}=52.6 ; \mathrm{SD}=13.9)$ and physical load $(\mathrm{M}=31.1, \mathrm{SD}=10.2)$ and between trauma patients $(\mathrm{M}=36.5$; $\mathrm{SD}=6.5)$ After ANOVA application, the effect of the prescription is examined on the type of cause. There is no a statistical difference for the four groups - $F$ $(31)=0.866 ; p=0.469$. There is no statistical significance between cause and physical activity $-\chi^{2}=3.445 ; p=0.314$. There is no statistical significance between the cause and the rate of VAS pain $-\chi^{2}=1.334 ; p=0.721$. There is no statistical significance between the cause and the hypertonus of $\mathrm{m}$. erector spinae $\chi^{2}=5.059 ; \mathrm{p}=0.168$. There is no statistical significance between the causes and hypertonus of $\mathrm{m}$. piriformis $-\chi^{2}=0.738, \mathrm{p}=$ $0.864)$. There is no a statistical significance between the cause and the hypertonus of m.quadratus lumborum $-\chi^{2}=6.100, p=0.107$ and $\mathrm{m}$. rectus abdominis $-\chi^{2}=4.209, \mathrm{p}=$ 0.240 . There is no statistical significance between the cause and the hypertonus of $\mathrm{m}$. illiopsoas $-\chi^{2}=3.448 ; \mathrm{p}=0.328$. and $\mathrm{m}$. gastroqnemius $-\chi^{2}=0.307 ; p=0.959$. There is no statistical significance between the cause and the hypertonus of $\mathrm{m}$. gluteus medius $-\chi^{2}=$ 7.022; $\mathrm{p}=0.071$. There is no statistical significance between the cause and the hypertonicity of $\mathrm{m}$. rectus femoris $-\chi^{2}=3.931$; $\mathrm{p}=0.269$. There is no statistical significance between the cause and the hypertonus of $\mathrm{mm}$. ishiocruralis $-\chi^{2}=0.425 ; \mathrm{p}=0.935$. There is no statistical significance between the cause and outcome of the Rolland Morris test $-\chi^{2}=$ 2.096 .

\section{DISCUSSION}

The presented study, aiming at the study and analysis of the functional condition in persons with pain in the lumbar region, established the demographic indicators and the clinical characteristics in 37 people of the Bulgarian population. The Rolland Morris questionnaire examines the extent of the difficulties in daily activities according to the self-assessment given by the surveyed persons. The results of the analysis of the indicators showed a negative impact of the pain in the lumbar region on the daily activity. Given the high degree of muscle imbalance in shortened muscles and poor quality of life, it is important to look for ways to improve the functional status of people with lumbar pain. Mihajlova, Filkova, Michaleva (5), Balagué, Mannion, Pellisé, Cedraschi (1), find as a pathogenetic factor for lumbar pain genetic predisposition, trauma (micro trauma), static and dynamic stress on the spine, inborn or acquired anomalies of the spine, overweight, etc.

A Roland Morris questionnaire examines the extent of the daily activities' difficulty 
according to the self-assessment given by the surveyed person. The results of the analysis of the indicators show a negative influence of the pain in the lumbar region on the daily activity. Krstev (6) publishes results with values between 15.34 and 17.20. In the studies of Tsimplis (7) in patients with chronic lumbar pain, dysfunctions were found mostly in the sciatic muscles, followed by the flexors and at least the adductors in the hip joint. This author gave the following data to 29 subjects: Flexors $18(62.06 \%)$ were affected Adductors 14 (48.27\%), Ischicruralis $21(72.41 \%)$. Similar are the findings of T. Krstev (6). In this study, it is found that the most pronounced degree of shortening is $\mathrm{mm}$. Ishiocruralis, $\mathrm{m}$. Piriformis, $\mathrm{m}$. Gluteus medius, m. Iliopsoas $\mathrm{m}$. Gastroqnemius. The pain VAS results found that the sensation of pain in women was more pronounced. Krstev (6) published data on the severity of pain according to the VAS between 7.74 and 5.6. Aoki, Sugiura, Nakagawa, et al. (8) set average values from $4.8 \pm 2.2$ to $5 \pm 2.4$ in two groups of patients - up to 65 years and over 65 years.

\section{CONCLUSIONS}

Pain in the lumbar region adversely affects the quality of life of the affected patients according to the results of the Roland Morris questionnaire.

The static load in women and the physical in men is probably the cause of lumbar pain.

Given the high degree of muscle imbalance in shortened muscles and poor quality of life, it is important to look for ways to improve the functional status of people with lumbar pain.

\section{REFERENCES}

1. https://www.ncbi.nlm.nih.gov/pubmed/219 82256 Lancet. 2012 Feb 4;379(9814):48291. doi: 10.1016/S0140-6736(11)60610-7.
Epub 2011 Oct 6, Balagué, F., Mannion, A., Pellisé, F., Cedraschi, C., Non-specific low back pain.

2. Radeva, S., Dikova, M., Matsuanova, B., Ilieva, T., acupuncture as a overgraduating treatment in patients with subacute pain in Lumbo-sacral syndrome, physical medicine, rehabilitation, health, ISSN 13120417, p 46 4/2015

3. Blair, S., Physical inactivity: the biggest public health problem of the 21 st century. Br J Sports Med 2009;43(1):1-2.

4. Nachemson, A., Epidemiology and the economics of low back pain. In: Herkowits, H., Dvorak, J., Bell, G., Nordin, M., Grob, D., editors. The Lumbar Spine. 3rd edition. Philadelphia, Pa, USA: Lippincott; 2004.

5. Mihajlova, M., Filkova, S., Michaleva, V., Some aspects of the conservative treatment and prevention of lumbar disc disease. Scripta Scientica Salutis Publicae, vol. 2, , suppl. 1, pp. 95-100, Medical University of Varna, 2016

6. Krstev,T.: Comparison of two treatment modalities for chronic pain syndrome. Sport Science 8 Suppl 2: pp. 55-58, 2015.

7. Tsimplis P. The place and role of the muscle dysfunction in the originating and development of the low back pain. Association of Physiotherapists in Bulgaria Seventh National Congress 5-7 June 2015, NSA Vasil Levski, Sofia, p 93, 2015

8. Aoki, Y., Sugiura, S., Nakagawa, K. et al., "Evaluation of Nonspecific Low Back Pain Using a New Detailed Visual Analogue Scale for Patients in Motion, Standing, and Sitting: Characterizing Nonspecific Low Back Pain in Elderly Patients," Pain Research and Treatment, vol. 2012, Article ID 680496, 4 pages, 2012. doi:10.1155/2012/680496. 